\title{
OTIMIZAÇÃO DE UMA CENTRAL DE CONTROLE DE MOTORES
}

\author{
Vitor Matos Serafin e Alexandre Brincalepe Campo \\ Cummins Brasil Ltda. \\ Instituto Federal de Educação, Ciência e Tecnologia de São Paulo \\ E-mails: vitor.m.serafin@cummins.com, brincalepe@ gmail.com
}

\section{RESUMO}

O trabalho apresenta um estudo de caso e o projeto de automação de uma Central de Controle de Motores (CCM). O sistema desenvolvido é usado para controle do bombeamento de água sob pressão, para a alimentação de trocadores de calor industriais e máquinas termodinâmicas do centro de pesquisa e desenvolvimento da América latina (LATC) da Cummins Brasil. A solução apresentada tem como objetivo o uso racional e sustentável dos recursos naturais, para economizar energia elétrica e reduzir o consumo de água potável do sistema. Estes objetivos podem ser atingidos por meio do controle do ciclo de trabalho (duty cycle) dos diversos motores elétricos da aplicação e do controle do set-point de pressão e da vazão de água nominal do processo, de acordo com a demanda térmica solicitada pelo sistema.

O sistema de controle projetado foi desenvolvido para atender a demanda de refrigeração térmica variável do processo. Ressalta-se que o consumo de água potável é proveniente em sua maior parte em decorrência do arraste de partículas de água por meio dos ventiladores das torres de refrigeração, evaporação e purga do sistema.

A planta do processo é descrita neste trabalho, onde são apresentadas as melhorias implementadas no sistema e os resultados obtidos. Após o processamento dos dados, foi constatada uma redução de $18 \%$ no consumo de energia elétrica e de $10.6 \%$ em água potável.

\section{INTRODUÇÃO}

Um dos principais componentes da Central de Controle de Motores (CCM) é um painel de acionamento de motores elétricos de baixa ou média tensão. Este sistema é responsável pelo gerenciamento e controle do bombeamento de água sob pressão, do LATC da Cummins Brasil. 
O CCM é largamente empregado em diversos segmentos da indústria que necessitam do fornecimento de água para a refrigeração de trocadores de calor e condensadores de máquinas térmicas. A NBR IEC 60439-1, da ABNT, é a norma regulamentadora.

O Centro Técnico de Pesquisa da América Latina é composto por nove bancos de teste dinamométricos (salas de teste), utilizados para prover diversos tipos de ensaios (gerais e específicos) em motores diesel, entre eles, curvas de plena carga (desempenho), testes de emissões, conforme NBR15634, DOE (design of experiment), testes de durabilidade, conformidade de produção (COP), simulação e etc.

O sistema demanda água em baixa temperatura sob pressão, consumindo energia elétrica 24 horas por dia, durante os três turnos de operação, em que o CCM se faz fundamental e indispensável para o funcionamento do departamento. O sistema de água sob pressão do prédio alimenta todos os dispositivos que requerem água para ser utilizada como refrigerante no processo de troca térmica. Este sistema é dividido basicamente em seis partes principais (tanque de água superior, tanque de água inferior, casa de máquinas, torres de resfriamento, estação de tratamento de água e salas de testes), como detalhado no diagrama da Fig. 1 abaixo:

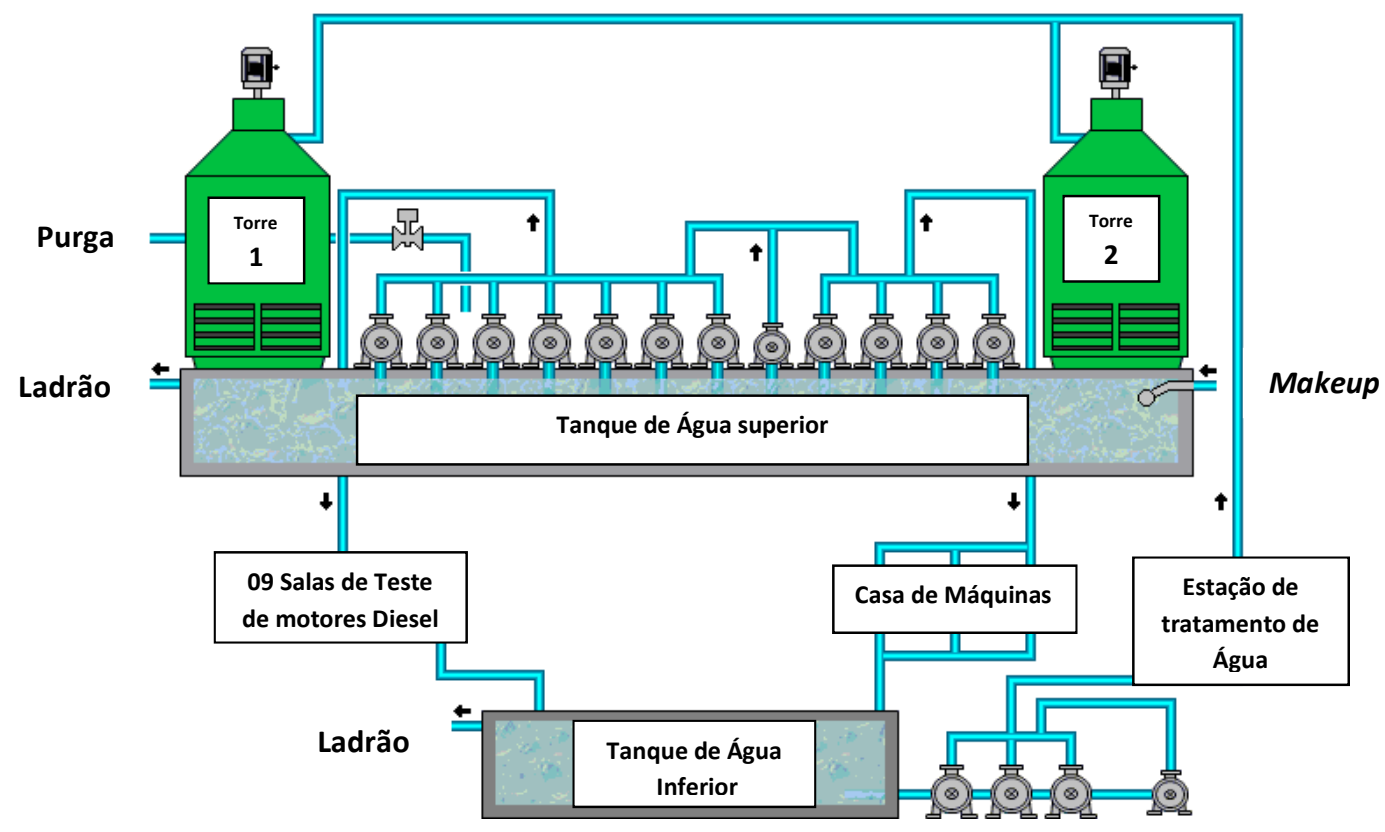

Figura 1 - Diagrama do Sistema de Água Sob Pressão

\section{Tanque de Água Superior}

O tanque de água superior, localizado no terceiro e último pavimento do prédio, tem capacidade de armazenamento de aproximadamente $82 \mathrm{~m}^{3}$ (82.000 litros) de água, onde estão instaladas 11 bombas centrífugas acopladas individualmente, a motores elétricos trifásicos de $10 \mathrm{CV}$ de potência. Estas bombas são responsáveis pela captação de água no reservatório superior para 
fornecimento sob pressão para as salas de testes de motores e para a casa de máquinas, por meio de duas tubulações distintas de 12 e 6 polegadas de diâmetro respectivamente.

Um conjunto de sete bombas interligadas em paralelo, dedicadas a pressurizar a tubulação de alimentação das salas de teste, que se ramifica para abastecer todos os trocadores de calor e máquinas térmicas, em que a pressão de trabalho deve ser entre 1.0 e 1.5 bar (no primeiro pavimento do prédio). As demais bombas (04), também interligadas em paralelo, são exclusivamente utilizadas para pressurizar o ramo de alimentação da casa de máquinas, onde a vazão mínima de água deve ser igual a $180 \mathrm{~m}^{3} / \mathrm{h}$, para atender à demanda necessária para refrigeração dos condensadores de 03 Chillers (instalados em paralelo no interior da casa de máquinas, localizada no primeiro pavimento).

\section{Bancos de Teste Dinamométricos}

As nove salas de teste requerem água sob pressão para refrigeração de quatro grandes sistemas, essenciais para a operação do prédio, conforme detalhado abaixo:

1. Refrigeração dos dinamômetros (equipamento utilizado para aplicar carga ao motor sob teste no banco de prova). O dinamômetro é o equipamento principal da sala de testes, pois, possibilita o atendimento aos ciclos de emissões (de acordo com a ABNT NBR ISO/IEC 17025) e a simulação em laboratório do duty cycle realizado pelo motor na aplicação. Além de possibilitar o levantamento da curva de potência e torque (curva de plena carga) do motor sob teste.

O dinamômetro dissipa calor durante o processo de frenagem do motor diesel e necessita de refrigeração interrupta, provida pelo sistema de água sob pressão, a uma pressão mínima de 1 bar.

2. Refrigeração dos trocadores de calor do tipo casco tubo (água - água) utilizados no sistema de refrigeração dos motores diesel. A função deste sistema de refrigeração é análoga àquela do conjunto radiador e ventoinha em um carro de passeio, arrefecendo e mantendo a temperatura da água circulante via galerias de água existentes no bloco e no cabeçote dos motores à combustão interna.

A utilização dos trocadores de calor tipo casco tubo (água - água) se faz necessária nas salas de testes de motores à combustão interna, já que o conjunto radiador e ventoinha da aplicação do veículo requerem vento frontal para prover a troca térmica e a refrigeração necessária ao motor, sendo assim, para testes de motores em local fechado (salas de teste), este trocador da aplicação não é utilizado.

3. Refrigeração dos trocadores de calor do tipo casco tubo (água - óleo), para refrigeração do sistema de suprimento de combustível aos motores. A linha de alimentação de combustível ao motor diesel possui controle de temperatura, para testes em bancos dinamométricos, ou seja, existe um controlador ( set-point $=40^{\circ} \mathrm{C}$ ) que atua em uma válvula de três vias, sendo duas vias 
de entrada de diesel. A primeira válvula de entrada é alimentada com o combustível quente (proveniente de um circuito com aquecedores de potência trifásicos) e a segunda com o fluído à temperatura ambiente.

O controlador recebe o feedback de temperatura da linha de alimentação (por um sensor de temperatura tipo PT-100) e atua sobre a válvula de três vias, misturando o combustível proveniente das duas entradas de modo a obter a temperatura de saída de acordo com o set-point pré-ajustado pelo usuário. De acordo com o princípio de funcionamento dos motores diesel, apenas parte do combustível enviado ao motor é consumido no processo de combustão, sendo assim, uma fração do fluído (não injetado na câmara de combustão) funciona como refrigerante de algumas peças do motor, entre elas o módulo eletrônico, que dissipa calor por meio de sua carcaça que fica em contato mecânico com a tubulação da linha de diesel.

Desse modo, o trocador de calor do tipo água-óleo se faz necessário nas salas de teste para a refrigeração do diesel de retorno do motor, tendo como objetivo a reutilização desta fração do combustível, que realimenta o processo (via válvula de 3 vias).

4. Refrigeração dos trocadores de calor para arrefecimento do sistema de ar proveniente da saída dos turbos compressores dos motores diesel (radiadores aletados do tipo água - ar).

A maioria dos motores diesel, em especial para aplicações automotivas, possui um turbo compressor incorporado ao motor de combustão interna. O objetivo é prover uma maior vazão mássica de ar à câmara de combustão do motor, sendo assim, pode-se injetar uma maior quantidade de combustível de modo a equilibrar a relação combustível + comburente e, com este artifício, obter-se maior potência.

Porém, após a compressão do ar, realizada pelo turbo compressor, ocorre o aumento de pressão e consequentemente da temperatura do ar, sendo que o fluído necessita de refrigeração para poder ser utilizado como comburente no processo de combustão. Esta refrigeração é feita por um trocador de calor refrigerado pela água que é fornecida pelo sistema de refrigeração sob pressão.

\section{Casa de Máquinas}

A casa de máquinas fica localizada no primeiro pavimento do prédio, sendo composta por 03 Chillers, responsáveis pelo fornecimento de água gelada para o sistema.

O Fan coil, que demanda água gelada, é uma máquina térmica que atua de maneira análoga a um sistema de ar condicionado, possibilitando a refrigeração do ar atmosférico que será admitido pelo turbo compressor do motor à combustão interna.

A carga térmica total fornecida pelos três Chillers é de $630.000 \mathrm{Kcal} / \mathrm{h}$ (Fornecimento de água gelada a $10^{\circ} \mathrm{C}$ para o processo). Demandando portanto, uma vazão de água de resfriamento de $180 \mathrm{~m}^{3} / \mathrm{h}$ por meio dos condensadores. 
O fornecimento de água sob pressão para refrigeração dos trocadores de calor das condensadoras dos três Chillers é feito via quatro bombas centrífugas, interligadas em paralelo, que captam a água no tanque superior e pressurizam a tubulação de 6" (dedicada para este sistema), conforme apresentado no diagrama da Fig.1.

\section{Tanque de Água Inferior}

No primeiro pavimento do prédio (térreo), encontra-se o tanque inferior, responsável pelo armazenamento da água posterior à troca térmica dos dois circuitos descritos anteriormente (salas de testes e casa de máquinas).

Neste local, estão instaladas três bombas centrífugas (acopladas, respectivamente, a motores elétricos de $25 \mathrm{CV}$ de potência), em paralelo, estas são responsáveis por bombear o fluído até a entrada das duas torres de resfriamento, localizadas no terceiro pavimento do prédio.

A capacidade do tanque inferior é de aproximadamente $34.9 \mathrm{~m}^{3}$ (34.000 litros) e a vazão nominal de cada bomba é de $210 \mathrm{~m}^{3} /$ hora. As tubulações de recalque de água possuem válvulas de retenção e válvulas de controle de fluxo instaladas em série, nas saídas das tubulações de recalque de água.

\section{Torres de Resfriamento}

As duas torres de resfriamento ficam localizadas no terceiro pavimento do prédio (Fig.2) e estão acopladas em paralelo. As torres possuem a função de resfriar a água posterior à troca térmica do processo (proveniente das três bombas localizadas no tanque inferior).

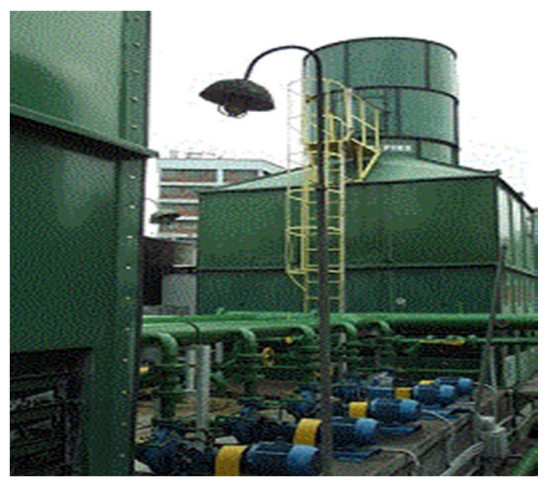

Figura 2 - Torres de Resfriamento

As torres de refrigeração utilizadas possuem aspiração mecânica, ou seja, possuem ventiladores (motores elétricos de 10HP) no topo da torre, responsáveis pela sucção do ar atmosférico, por meio de janelas localizadas na base da torre. Dessa maneira, ocorre o fluxo de contracorrente (mesma direção, porém sentidos opostos) entre o ar captado pelos ventiladores e a queda de água a ser refrigerada, conforme o fluxograma apresentado na Figura 3.

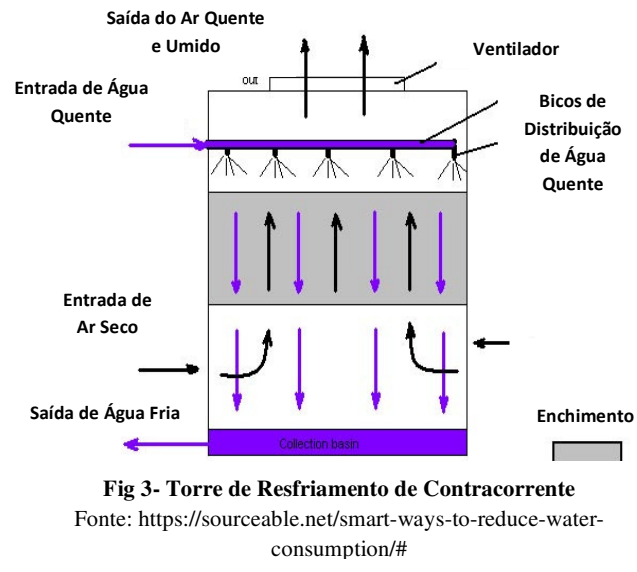

As torres de refrigeração ficam posicionadas acima do tanque superior, sendo que a água refrigerada pela torre retorna (por gravidade) ao tanque superior, para reutilização, encerrando o processo do sistema de água sob pressão. 
Porém, existem perdas no sistema de fornecimento de água, ou seja, nem toda a água captada no tanque superior e utilizada como refrigerante nos trocadores de calor industriais e posteriormente refrigerada através das torres de resfriamento retorna ao tanque de abastecimento para reutilização. Temos diversos fatores que contribuem para a perda de água no sistema, tais como evaporação ocorrida nas torres de resfriamento (durante o processo de troca térmica e mássica), arraste (via ventiladores das torres) e perda durante o processo de purga do sistema.

Para a reposição do volume de água perdido, o tanque superior é abastecido com água proveniente da concessionária. Este abastecimento é feito por uma tubulação de 2" (makeup) e controlado por uma válvula tipo boia, instalada na saída da tubulação que alimenta o tanque superior, mantendo o sistema cheio.

\section{Estação de Tratamento de Água}

O tanque superior é interligado também a uma estação de tratamento de água e por dois filtros de material particulado, para filtragem de detritos sólidos presentes na água.

A estação de tratamento mostra uma fração da água armazenada no tanque superior e por diversos sensores, localizados ao longo da plataforma, efetua a medição e aquisição dos dados de $\mathrm{Ph}$, condutividade, turbidez, temperatura, total de dispersantes químicos presentes na amostra, taxa de corrosão para aço carbono e cobre.

A plataforma efetua a dosagem de dois dispersantes químicos, de acordo com o nível de contaminantes presentes na água, esta dosagem é realizada de acordo com o feedback dos sensores. A injeção do primeiro composto visa à prevenção das tubulações e dos trocadores de calor do sistema de água sob pressão do efeito da corrosão química, enquanto o segundo (biocida) tem como objetivo, inibir o crescimento dos micro-organismos que se encontram nos tanques (controle bacteriano).

A estação de tratamento monitora e controla a condutividade da água $(\mu \mathrm{S} / \mathrm{cm})$, esta é uma característica físico-química da água, que indica a capacidade da mesma em conduzir uma corrente elétrica. Este parâmetro é muito importante para o sistema, pois, está relacionado com a taxa de corrosão química do sistema.

Sendo assim, nos casos em que a condutividade da água é muito elevada, a estação de tratamento efetua automaticamente a drenagem (blowdown) parcial da água do tanque superior por meio do acionamento elétrico de uma solenoide, instalada na tubulação de dreno do tanque. A tendência com a drenagem parcial é o aumento da qualidade da água do sistema, visto que o mesmo é alimentado continuamente com água potável, proveniente da tubulação de makeup. O processo de blowdown é realizado até obter-se, no sistema, uma mistura composta por água limpa (proveniente da concessionária) mais água existente no processo com uma condutividade resultante menor que $1000(\mu \mathrm{S} / \mathrm{cm})$. 


\section{OBJETIVOS}

O objetivo do trabalho é apresentar um conjunto de soluções aplicadas numa Central de Controle de Motores (CCM) para possibilitar o uso racional e sustentável dos recursos naturais, tais como energia elétrica e o consumo de água potável da planta. O sistema será controlado por meio da regulação do ciclo de trabalho (duty cycle) dos diversos motores elétricos, assim como do ajuste dos valores de referência de pressão e da vazão de água nominal do processo, de acordo com a demanda térmica solicitada pelo sistema.

A solução proposta envolve a aplicação de tecnologias de supervisão e controle da planta, atuando de maneira eficaz no acionamento das bombas, com sensores distribuídos ao longo do processo. O controle é desenvolvido para obter o mínimo de perda de água potável, fornecendo a vazão e pressão de água ideal (otimizada) para os consumidores (trocadores de calor), distribuídos nos três pavimentos do prédio, diminuindo à vazão de reposição (makeup).

Sabe-se que a rejeição térmica na planta em questão é variável, visto que depende da quantidade de motores sob teste em determinado instante. O centro de desenvolvimento e pesquisa é composto por nove salas de teste de motores diesel, motores estes com potência na escala de (150 a 550HP). Para exemplificar o controle do ciclo de trabalho proposto, duas situações hipotéticas de operação diferentes serão utilizadas como exemplo, baseadas em dados empíricos coletados no sistema, conforme descrito abaixo:

\subsection{Situação Hipotética de Plena Carga e Condições Climáticas Desfavoráveis.}

$\checkmark$ Quantidade de Salas de Teste em operação: 09 (Plena Carga);

$\checkmark$ Potência Aproximada de motores em Operação: 2255 HP;

$\checkmark$ Rejeição Térmica aproximada do sistema: 334220 Kcal.

$\checkmark$ Estação do ano: Verão - Temperatura Ambiente elevada $\left(\mathbf{3 4}^{\circ} \mathbf{C}\right)$;

$\checkmark$ Umidade Relativa do Ar elevada (70\%)

$\checkmark$ Temperatura da água do processo elevada $\left(29.8^{\circ} \mathbf{C}\right)$.

\subsection{Situação Hipotética de Operação Parcial e Condições Climáticas Favoráveis.}

$\checkmark$ Quantidade de Salas de Teste em operação: 01 (Carga Parcial);

$\checkmark$ Potência Aproximada de motores em Operação: 300 HP;

$\checkmark$ Rejeição Térmica aproximada do sistema: 19660 Kcal.

$\checkmark$ Estação do ano: Outono/Inverno - Temperatura Ambiente baixa $\left(\mathbf{2 3}^{\circ} \mathbf{C}\right)$;

$\checkmark$ Umidade Relativa do Ar baixa (40\%);

$\checkmark$ Temperatura da água do processo baixa $\left(\mathbf{2 4}^{\circ} \mathbf{C}\right)$.

De acordo com os ciclos de trabalho detalhados acima, podemos constatar, com base nos dados empíricos do processo apresentados, que a rejeição térmica Q (Kcal) apresentada na situação 1.1 (hipotética de plena carga) é $1600 \%$ superior à rejeição térmica indicada na situação 1.2. Sendo assim, é razoável considerar a hipótese de controle e otimização do ciclo de trabalho 
(Duty Cycle - D), em função tanto da demanda térmica do processo (Kcal) quanto das condições atmosféricas para um determinado dia ao longo do ano.

Com a otimização da central de controle de motores (CCM) e implementação dos controladores PID no processo em questão, será possível controlar o duty cycle de trabalho das torres de resfriamento de acordo com a carga térmica, estação do ano e condições climáticas. Vale lembrar que a utilização das torres de resfriamento se faz muito maior em um dia quente (verão) com uma alta demanda de carga térmica, ou seja, alta eficiência (produção) do prédio em comparação a um dia frio (inverno) com baixa demanda de carga térmica. Estes dois cenários tão distintos levam à hipótese de que otimizando o duty cycle de trabalho das torres de refrigeração e controle em malha fechada do sistema, é possível atingir uma economia no consumo de água potável e energia elétrica.

\subsection{Economia de Água Potável}

A economia de água potável é obtida por meio do controle do duty cycle de operação do sistema, provendo a quantidade de água otimizada para o processo (de acordo com a demanda térmica e condições atmosféricas), ou seja, sem excessos.

Desse modo, efetua-se a diminuição acentuada na vazão de água circulante na planta. Esta diminuição na vazão é possível por meio da modulação, com inversores de frequência, dos motores elétricos acoplados às bombas centrífugas de captação do fluído.

Com a diminuição na quantidade de água captada pelas bombas, temos a atenuação no efeito do arraste de gotículas d'água pelos ventiladores das torres de resfriamento, pois, a vazão circulante nas torres de resfriamento será diminuída, facilitando o escoamento do fluído através dos canais e bicos de distribuição, atenuando as perdas por arraste.

"O ar que sai pelo topo da torre é quente e úmido. Encontrando-se com o ar ambiente mais frio, boa parte da umidade condensa-se e forma o penacho de vapor que flutua com o vento" (FOUST A.S.1982,p.371). A Fig. 4 ilustra o efeito da pluma na saída das torres de resfriamento da planta sob estudo.

Combinado à ação de diminuição da vazão de água do processo, faz-se também a diminuição da rotação de operação dos motores acoplados aos ventiladores das torres de resfriamento, desse

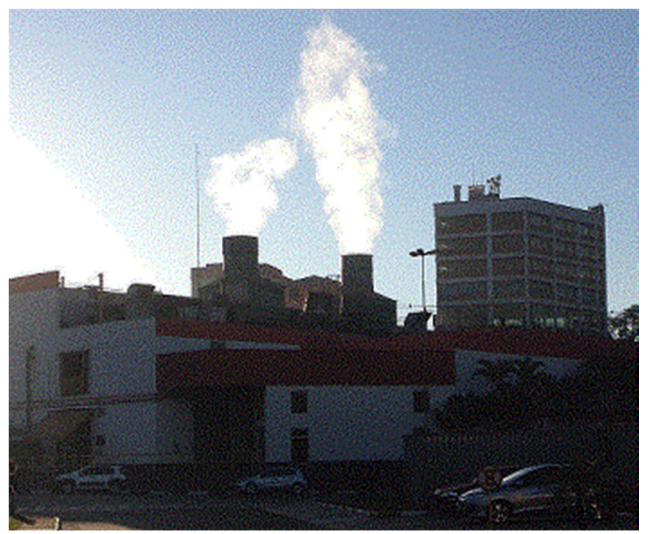

Figura 4 - Pluma Saída das Torres de Resfriamento modo ocorre a redução no arraste de água e diminuição da névoa do ar descarregado pelo ventilador. 


\subsection{Economia de Energia Elétrica}

Logo, para um dia de trabalho onde a demanda térmica (Kcal) é baixa e as condições atmosféricas são favoráveis (Situação 2), ou seja, tanto a temperatura da água do processo, quanto a temperatura ambiente são baixas, não é mandatória a utilização das sete bombas de captação de água potável e três bombas de recalque, bem como a operação das duas torres de refrigeração com os motores energizados na condição de potência máxima.

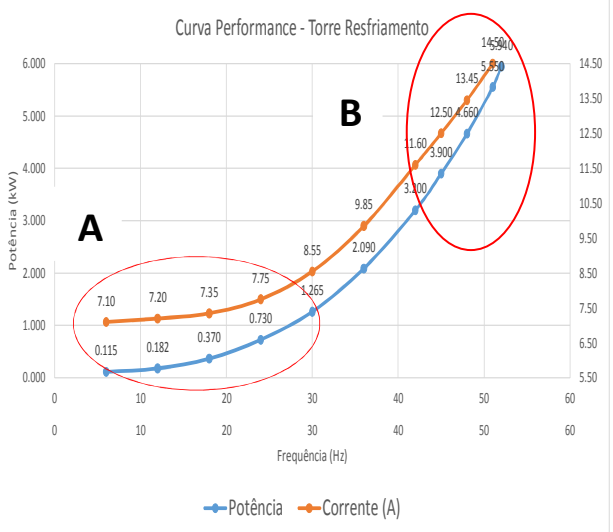

Figura 5 - Curva de Performance do Motor de Acionamento das Torres de Resfriamento

A Figura 5 ilustra a curva de performance do motor elétrico de $10 \mathrm{CV}$, responsável pelo acionamento dos ventiladores. O gráfico evidencia um aumento exponencial na corrente elétrica em função do aumento da frequência, logo, para um pequeno incremento na rotação do motor, acarreta um aumento significativo na potência consumida.

Sendo assim, a economia de energia elétrica é obtida evitando-se a região circular, indicada com a letra "B" no gráfico, pois a curva de performance do motor apresenta um maior incremento na potência consumidaem relação a uma pequena variação da frequência aplicada, diferentemente da região com a letra " $A$ " onde a taxa é muito menor.

Desse modo é possível fornecer água sob pressão para a demanda apresentada na Situação 2, com mais da metade dos motores do sistema desligados, provendo uma economia significativa de energia elétrica.

A redução no consumo de energia elétrica, também é possível por meio da diminuição no número de partidas efetuadas nos motores elétricos da planta, visto que, além do consumo elevado em $\mathrm{kWh}$, acarreta fadiga nos fios e cabos elétricos do sistema de potência e aumento na temperatura de operação dos motores elétricos.

\section{MÉTODO}

Para um maior entendimento, a determinação das características do processo em questão e posterior modelagem do sistema, foram coletadas as seguintes informações:

\subsection{Volume $\left(\mathrm{m}^{3}\right)$ dos tanques de água (superior e inferior)}

Os tanques de armazenamento de água possuem formatos retangulares, logo, o volume foi calculado, multiplicando-se (comprimento x largura $\mathbf{x}$ altura). O volume do tanque superior, onde está armazenada a água que será captada pelas bombas e, posteriormente, enviada sob 
pressão aos trocadores de calor é de $81.7 \mathrm{~m}^{3}$. Enquanto que o tanque inferior, que armazena a água posteriormente à troca térmica, possui um volume de $34.9 \mathrm{~m}^{3}$.

\subsection{O volume de água contido nos dutos de distribuição de água do sistema}

O volume de água existente nos dutos de alimentação, retorno e purga do sistema foi calculado, aplicando-se a seguinte fórmula: ( $\left.\pi \times \mathbf{R}^{2} \mathbf{x} \mathbf{L}\right)$, em que $\mathbf{L}$ é o comprimento da tubulação e $\mathbf{R}$ é o raio da tubulação. A fórmula foi aplicada nos diversos trechos da tubulação, somando-se cada segmento. O volume total de água alocado nas tubulações do sistema é de $6.314 \mathrm{~m}^{3}$. Desse modo, o volume total de água contida no sistema é de aproximadamente $123 \mathrm{~m}^{3}$.

\subsection{Levantamento da vazão total de água do sistema (litros / min)}

A vazão de água volumétrica do processo foi calculada por meio de um método empírico, em que foi cronometrado o tempo necessário para enchimento do tanque inferior, com a água proveniente do processo, após a troca térmica. Obteve-se a vazão aplicando-se a seguinte fórmula: $($ Vazão $=$ Vol / t $)$, em que Vol é o volume do tanque inferior em litros e t é o tempo em minutos. A vazão do processo calculada é de 3300 litros/minuto, submetido à pressão de 1.5Bar.

\subsection{Determinação da perda de água do sistema Makeup (litros/min)}

A perda de água do processo foi calculada por meio da medição da vazão de água de alimentação (makeup) do tanque superior. Como já foi exposto anteriormente, sabe-se que existem perdas no sistema de bombeamento de água sob pressão, ou seja, nem toda a água captada no tanque superior e bombeada aos trocadores de calor retorna ao tanque para reutilização.

O tanque superior do sistema possui uma conexão de alimentação de água potável, proveniente da concessionária. Para controle do nível do tanque, o sistema possui uma válvula tipo boia, instalada na saída desta conexão em série com um medidor de volume de água tipo hidrômetro. Sendo assim, foi cronometrado o tempo necessário para o volume de complemento de $1 \mathrm{~m}^{3}$. A vazão de complemento de água do processo varia entre (20 a 56 litros/minuto).

\subsection{Levantamento da curva característica das Torres de Resfriamento}

O primeiro passo para o levantamento da curva característica das torres e refrigeração do processo foi a consulta aos dados nominais das mesmas, informado nas plaquetas de identificação anexa às torres e por meio do levantamento dos dimensionais do equipamento, para consulta do datasheet do fabricante. 
Sendo assim, foi possível obter os seguintes dados nominais das torres de resfriamento:

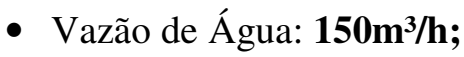

- Temperatura de água quente: $60^{\circ} \mathbf{C}$;

- Temperatura de água fria: $\mathbf{3 0}^{\circ} \mathbf{C}$;

- Temperatura de bulbo úmido: $\mathbf{2 4}^{\circ} \mathbf{C}$;

- Pressão máx de admissão de água: 0,5mca;

- Potência dos ventiladores: 10CV;

- Rotação dos motores: 1160RPM @ 60Hz;

O enchimento empregado nas torres de resfriamento em questão é do tipo SG/300, largamente empregado em aplicações industriais. Composto por grades de polipropileno, sua função é acelerar o processo de troca de calor entre a água quente a ser refrigerada e o ar admitido pelos ventiladores através do fluxo de ar cruzado.

A torre de resfriamento do processo em questão é composta por 36 bicos de distribuição de água, fixados ao longo dos canais de destruição. Os bicos são distribuídos de maneira homogênea, no interior do resfriador e tem a função de prover o escoamento uniforme da vazão de água quente que adentra a torre de resfriamento e entrará em contato com o enchimento de polipropileno, provendo uma melhor eficiência térmica.

Eliminadores de gotas de polipropileno, são montados no interior das torres de resfriamento, entre os ventiladores e os bicos de distribuição de água. Sua função é atenuar o efeito do arraste de água da torre por meio dos ventiladores.

\subsection{Levantamento das Curvas Nominais das Bombas de Captação de Água.}

O procedimento utilizado para o levantamento da curva característica das bombas centrífugas foi análogo ao utilizado para levantamento das características das torres de resfriamento, coletando os dados de plaqueta dos equipamentos. Desse modo, foi possível obter os dados nominais das três bombas responsáveis pela transferência de água do tanque inferior até as torres de resfriamento, das sete bombas de transporte de água do tanque superior até os trocadores de calor das salas de testes e das quatro responsáveis pelo bombeamento do fluído à casa de máquinas.

Com os dados nominais e curvas características das bombas de captação de água e das torres de resfriamento do processo, foi necessário avaliar se a faixa de operação das mesmas eram satisfatórias para atender aos requerimentos técnicos da planta. Uma vez que o sistema de água sob pressão deve atender aos quatro grandes sistemas contidos nos bancos de teste dinamométricos, conforme apresentados na página 3, além de suprir a casa de máquinas, localizada no primeiro pavimento do prédio. 
Os requerimentos técnicos do sistema, para fornecimento de água sob pressão aos dinamômetros, Chillers e trocadores de calor da planta são apresentados abaixo:

- Pressão de trabalho: 1.5 à 2.5 bar;

- Vazão de água máxima: (salas de teste $=420 \mathrm{~m}^{3} / \mathrm{h}$ );

- Vazão de água máxima: (casa de máquinas $=180 \mathrm{~m}^{3} / \mathrm{h}$ );

- Temperatura da água: 24 à $29^{\circ} \mathrm{C}$.

Os requerimentos técnicos da planta foram calculados após a análise detalhada da curva de trabalho dos dinamômetros, dados técnicos apresentados pelo fabricante dos Chillers (modelo SAT.240) e especificação técnica dos trocadores de calor.

Para atendimento aos requisitos técnicos, um novo projeto de bombas de captação de água foi desenvolvido para a planta, onde optou-se pela utilização de uma menor quantidade de bombas, porém, com maior capacidade de vazão de água e altura manométrica. Desse modo foram especificadas quatro bombas de $84 \mathrm{~m}^{3} / \mathrm{h}$ para o ramo de alimentação das salas de teste e quatro bombas de $45 \mathrm{~m}^{3} / \mathrm{h}$ para o ramo de alimentação dos Chillers, todas com pressão de recalque igual a 3bar, do tipo Megablock e acoplados a motores elétricos de alta eficiência (IE2).

Nesta fase de projeto também foi proposta um bomba de pré-partida para o sistema, cuja função é garantir o enchimento dos pescadores de 6" das bombas de captação de água do tanque superior, atendendo desse modo o parâmetro NPSH (net positive suction head), referente à pressão mínima necessária na entrada das bombas centrífugas.

\subsection{Mapeamento térmico dos motores elétricos do processo}

Com o auxílio de uma câmera térmica, foi realizado o mapeamento térmico da temperatura de operação dos motores elétricos (conforme apresentado na Fig. 6), bombas centrífugas, condensadores dos chillers e das torres de resfriamento.

Este levantamento foi realizado com o objetivo de verificar as temperaturas dos componentes do sistema e abrir um comparativo do antes e depois do controle do duty cycle proposto ao sistema,

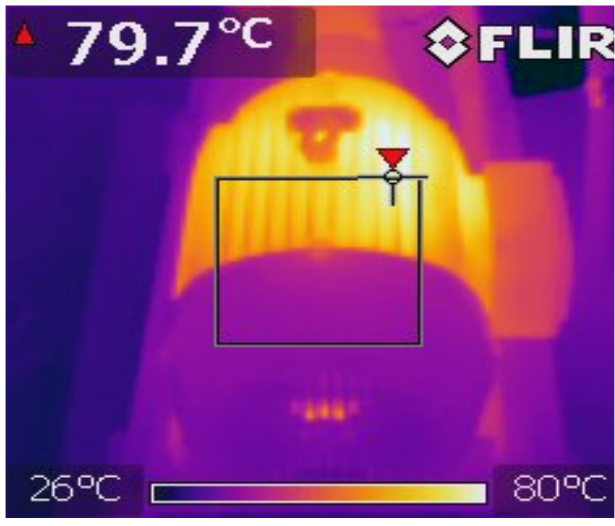

Figura 6 - Temp. de Operação (Motor de 25CV) servindo de base line (As found) para o projeto de otimização do CCM.

Vale lembrar que o modo de controle inicial do CCM (antes do estudo de caso e do projeto proposto) era do tipo ON/OFF, ou seja, sem a possibilidade de operação dos motores elétricos em condições parciais de carga. 
Assim, os motores operavam à plena carga, 24 horas por dia, 7 dias por semana, independente da demanda térmica e condições atmosféricas.

\section{DOE - Design of Experiments}

Por meio do mapeamento diário do sistema de fornecimento de água sob pressão do centro de pesquisa, por um período de três meses, foi possível com o auxílio do programa estatístico Minitab levantar as variáveis majoritárias para o consumo de água potável do sistema. As variáveis de interesse monitoradas estão listadas abaixo:

\subsection{Variáveis de entrada para o DOE:}

- Variação $(\Delta \mathrm{t})$ entre a temperatura de alimentação e retorno do sistema;

- Quantidade e potência dos motores sob teste (carga térmica total);

- Temperatura ambiente (bulbo seco) e Umidade Relativa;

- Vazão de água do processo;

\subsection{Variável de Saída para o DOE:}

- Vazão de makeup (litros/minuto)

\subsection{Critérios adotados:}

A variável $\Delta \mathrm{t}$ (Temp) indica o trabalho realizado pela planta, pois, é proporcional a rejeição térmica do processo.

\section{$\Delta t($ Temp $)=$ Temperatura do tanque inferior - Temperatura do tanque superior}

$\Delta \mathrm{t}>2,0^{\circ} \mathrm{C} \quad$ Considerado Nivel Lógico 1 (Rejeição Térmica elevada);

$\Delta \mathrm{t}<2,0^{\circ} \mathrm{C} \quad$ Considerado Nivel Lógico 0 (Rejeição Térmica baixa);

\section{Temperatura Ambiente:}

Temp. Ambiente $>22,0^{\circ} \mathrm{C}$ Considerado Nivel Lógico 1 (Temperatura Ambiente elevada);

Temp. Ambiente $<22,0^{\circ} \mathrm{C} \quad$ Considerado Nivel Lógico 0 (Temperatura Ambiente baixa);

\section{Umidade Relativa do Ar:}

Umidade $>55 \% \quad$ Considerado Nivel Lógico 1 (Umidade elevada);

Umidade $<55 \% \quad$ Considerado Nivel Lógico 0 (Umidade baixa). 


\section{Automação e Sistema de Supervisão}

Com o objetivo de prover para o usuário um maior entendimento da dinâmica do sistema de bombeamento de água sob pressão e monitoramento em tempo real das variáveis mais importantes, foi desenvolvida uma automação para o CCM em questão, com um sistema de controle e supervisão, desenvolvido em linguagem de programação ladder, por meio de um controlador lógico programável (CLP).

\subsection{MENU PRINCIPAL}

Navegando pelo menu principal do sistema de automação, é possível acessar outras seis páginas referentes ao sistema de supervisão do sistema de água sob pressão, conforme detalhado abaixo:

\subsubsection{Sinótico}

A tela de sinótico (Fig.7) é a tela de supervisão principal do sistema, pois é possível ter um entendimento e feedback completo e em detalhes da planta, pela indicação dos sensores de temperatura, nível dos tanques, pressões, quantidade de bombas ligadas, rotações dos motores elétricos, vazão de makeup, alarmes, consumo de água, fluxo do fluído, purga etc.

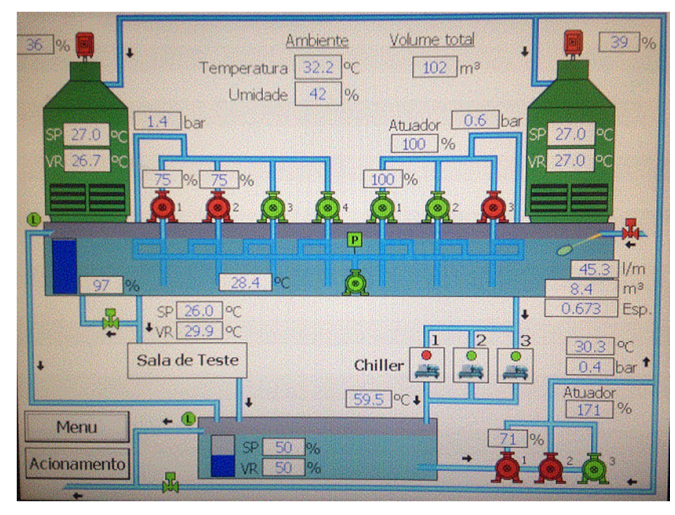

Figura 7 - Sinótico (Supervisório)

\subsubsection{Acionamentos}

Pela tela de acionamentos, é possível ligar/desligar todos os dispositivos da planta, tais como bombas (resfriamento, sistema de chiller e retorno), ventiladores da torre, válvulas (purga e makeup). Além de possibilitar a leitura das variáveis de temperatura, pressão e nível, é possível ajustar os alarmes (alto e Baixo) para cada variável monitorada no processo.

\subsubsection{Horímetros/Registros}

A tela de horímetro indica as horas de uso de cada bomba e motor elétrico da aplicação, com isso é possível efetuar o controle de maneira eficaz da manutenção preventiva de cada componente. É possível, também via horímetro de cada bomba, efetuar o uso equilibrado das mesmas, pela implementação de um rodízio.

\subsubsection{Alarmes}

Os alarmes ativos e inativos do sistema são exibidos na tela de alarmes. Vale lembrar que todos os alarmes, quando diagnosticados, são inclusos nesta lista e a buzina de emergência da automação é acionada para alerta aos usuários. 


\subsubsection{Temperaturas}

Pela tela de temperaturas (Fig. 8), é possível ter o feedback da rejeição térmica efetuada em cada uma das nove salas de teste. Os bancos dinamométricos foram equipados com sensores de temperatura, instalados nas tubulações de saída de água, ou seja, após efetuada a troca térmica com os sistemas de resfriamento do banco de prova.

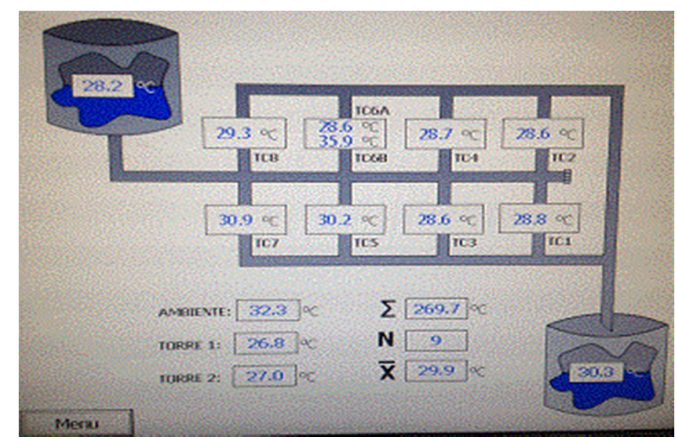

Figura 8- Tela de Temperaturas Salas de Teste

Assim, o controlador possui um algoritmo que faz uma estimativa em real time da temperatura média de retorno, esta variável atua como feedback para o controlador em questão, que analisa a necessidade de aumento ou diminuição da vazão de água do processo. Logo, se a média de temperatura calculada for inferior ao set-point estabelecido, o controlador PID (tipo split-range) irá atuar sobre os inversores de frequência, diminuindo a rotação das bombas de captação de água, atenuando a vazão do fluído por meio das salas de teste.

Como resultado, tem-se a diminuição no consumo de energia elétrica, visto que a corrente dos motores elétricos será diminuída, reduzindo o consumo de água potável.

De maneira análoga, se a média de temperatura calculada for superior ao set-point estabelecido, o controlador PID irá atuar aumentando a rotação dos motores, provendo uma maior vazão de água no sistema, atendendo ao aumento da demanda térmica.

\subsubsection{ETA - Estação de Tratamento de Água}

A tela de interface com a estação de tratamento de água (Fig.9) foi desenvolvida tomando-se como base o design do hardware da ETA, de maneira a possibilitar ao usuário um melhor entendimento da planta e da distribuição dos sensores responsáveis pelo monitoramento dos dados referentes à qualidade da água do processo. Os dados são transmitidos via comunicação serial RS485 e possibilitam a visualização dos parâmetros de temperatura da amostra, indicadores de taxa de corrosão, condutividade, $\mathrm{Ph}$, turbidez, índice de óxido redução, quantidade de polímeros presentes

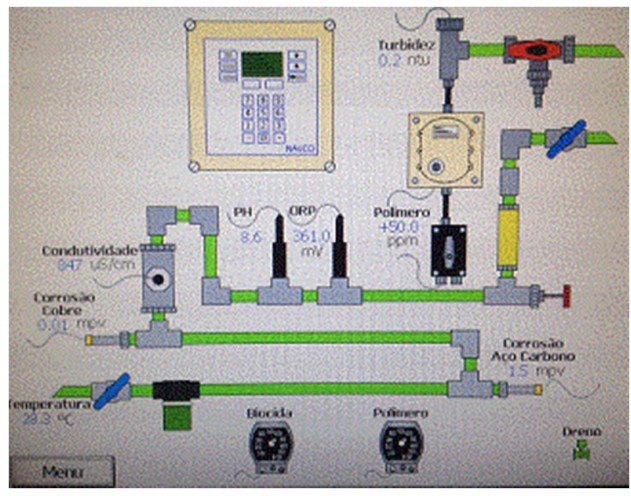

Figura 9 - Software Desenvolvido Estação de Tratamento de Água na água e status da válvula de purga (blowdown). 
É possível também verificar o status de cada uma das bombas dosadoras de dispersantes químicos. Dessa forma, quando ocorrer a drenagem do sistema (blowdown), tem-se o histórico e o indicativo que justificará o aumento no consumo de água potável (makeup) naquele período.

\section{CONTROLADOR DAS TORRES DE RESFRIAMENTO}

Foi implementado também um controlador exclusivo para as torres de resfriamento, onde o usuário estipula o set-point desejado para a temperatura da água nas saídas das torres de resfriamento e o controlador PID atua, por meio dos inversores de frequência, no acionamento dos motores elétricos de $10 \mathrm{CV}$, responsáveis pela rotação dos ventiladores das torres.

No sinótico, é possível verificar o valor do set-point ajustado (SP) e o valor da temperatura real (VR), amostrada por um sensor do tipo PT-100, instalado diretamente na saída das torres.

O controlador possui também um set-point de temperatura mínima (libera), para habilitar a malha fechada do controlador. Desse modo, se a temperatura real (VR) na saída das torres for inferior à temperatura mínima pré-ajustada (libera), o controlador irá desligar os ventiladores, uma vez que, neste ponto de operação, o sistema não necessitará de refrigeração (fluxo de contracorrente), já que apenas a circulação da água por meio das torres será suficiente para manter o sistema resfriado. Assim, é possível obter uma economia significativa no consumo de energia elétrica.

Outro benefício do sistema de controle de acionamento das torres é a alteração automática do set-point para o horário de pico (17h30 às 20h30), sendo possível aumentar o set-point de temperatura no horário de ponta, exigindo assim um menor rendimento das torres neste intervalo de tempo, em que o custo do kWh é elevado. Vale lembrar que o sistema possui aproximadamente $123 \mathrm{~m}^{3}$ e este intervalo de 3 horas é curto para causar uma variação de temperatura $(\Delta \mathrm{t})$ significante ao processo.

\section{Resultados}

Com o auxílio de um analisador de energia com data logger, foi possível efetuar um comparativo no consumo de energia do CCM (antes vs depois) do sistema de controle implementado. Foram coletados dados por um período de 7 dias.

O CCM apresentou um consumo total de 17,493 MWh (antes da implementação) e 14,333 MWh (com o sistema automatizado). Comparativamente, verificou-se que o novo painel apresentou uma redução no consumo de energia elétrica de aproximadamente $18 \%$. Esta redução apresenta uma economia anual de $\mathrm{R} \$ 105.453,71$ (custo do $\mathrm{kWh}$ médio atribuído = $\mathrm{R} \$ 0,64)$. 
Os resultados apresentados pelo analisador de energia indicaram também o aumento no fator de potência (0.862 para 0.956). Este é um indicador importante para instalações industriais, o fator de potência ideal (1) indica um menor consumo de energia reativa.

Após a otimização do processo, foi levantado novamente o mapeamento térmico da temperatura de operação dos motores elétricos (de maneira análoga à apresentada no item 2.8). Os motores de $25 \mathrm{CV}$, responsáveis pelo recalque de água do tanque inferior ao tanque superior, apresentaram uma atenuação na temperatura de operação na ordem de $28 \%$ (comparativo de temperatura apresentado entre a Fig.6 e Fig.10).

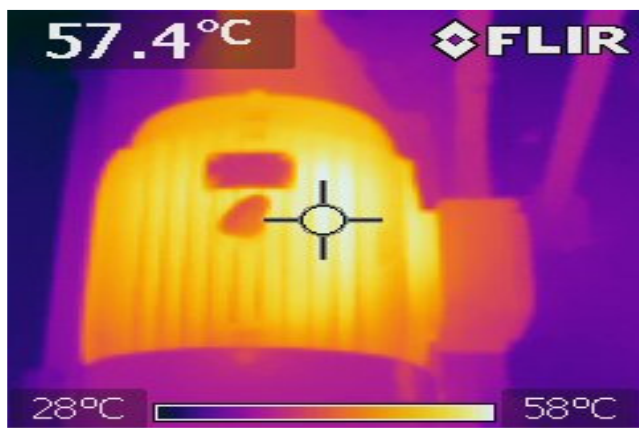

Figura 10 - Temperatura de Operação do Motor Elétrico de 25CV (Após a Otimização do Processo)

Essa diminuição na temperatura de operação dos componentes contribui não apenas na economia direta de energia elétrica (dissipada na forma de calor), como também no aumento da vida útil de todos os componentes do circuito de potência de alimentação dos motores elétricos da aplicação, provendo uma economia atrelada também à manutenção corretiva do sistema.

A economia de água potável do sistema foi de 10,6\%. Comparativo este entre o acumulado no primeiro trimestre de 2016 e o consumo apresentado no mesmo período de 2015, para uma mesma eficiência (produção) do prédio LATC. Esta economia percentual representa uma redução de $\mathrm{R}$ \$38.459,03 (1.614 $\mathrm{m}^{3}$ de água) no acumulado em um ano (full year).

Dessa forma, a economia anual do projeto (energia elétrica + água potável) é de R $\$ 143.912,75$ (payback $=6,4$ anos).

O projeto desenvolvido foi submetido também para análise do ministério da ciência e tecnologia, uma vez que, trata-se de pesquisa e desenvolvimento de inovação tecnológica e poderá dessa forma pleitear incentivos fiscais, conforme disciplinado no decreto $\mathrm{n}^{\circ} 5.798$ (lei do bem).

\subsection{Resultados DOE}

O resultado apresentado pelo software de análise de estatística (Fig. 11) indica que a variação $(\Delta t)$ entre a temperatura de alimentação e retorno do sistema é majoritária (onde $1=$ Alto e $0=$ Baixo), logo, possui uma maior influência no consumo de

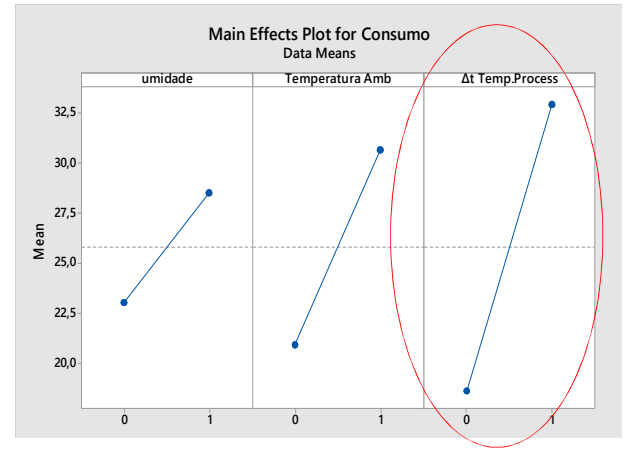

Figura 11 - Variáveis Majoritárias para Consumo de Água Potável 
água potável do sistema, ou seja, quanto maior a carga térmica dissipada (trabalho realizado), maior o consumo. De acordo com o gráfico, variando-se $\Delta \mathrm{t}$ (eixo das abscissas) acarreta a maior variação no consumo de água (eixo das ordenadas).

As variáveis temperatura ambiente e umidade relativa do ar vêm na sequência como segunda e terceira maiores influências, respectivamente. $\mathrm{O}$ software também apresenta uma tabela de interação (Fig.12) entre as variáveis majoritárias, sendo possível observar o comportamento do consumo para o pior caso $(\Delta \mathrm{t}$ e temperatura ambiente elevados).

De acordo com o gráfico da figura 13, é possível constatar que o ponto "A" apresenta o menor consumo de água potável (11 litros/min) este resultado é obtido quando a temperatura ambiente, umidade e $\Delta \mathrm{t}$ são baixos (todos com nível lógico baixo $=0$ ).

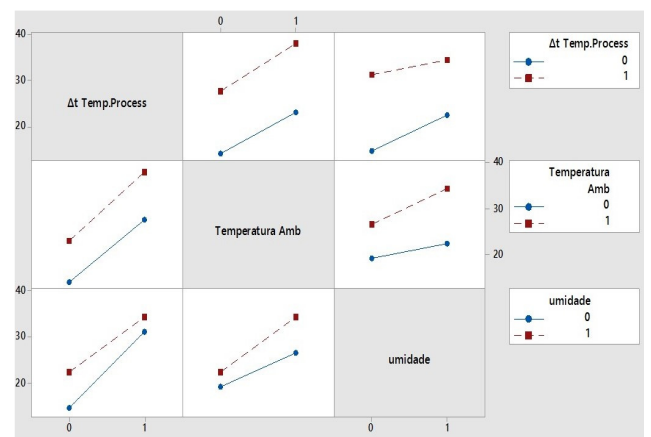

Figura 12 - Interação das Variáveis Majoritárias

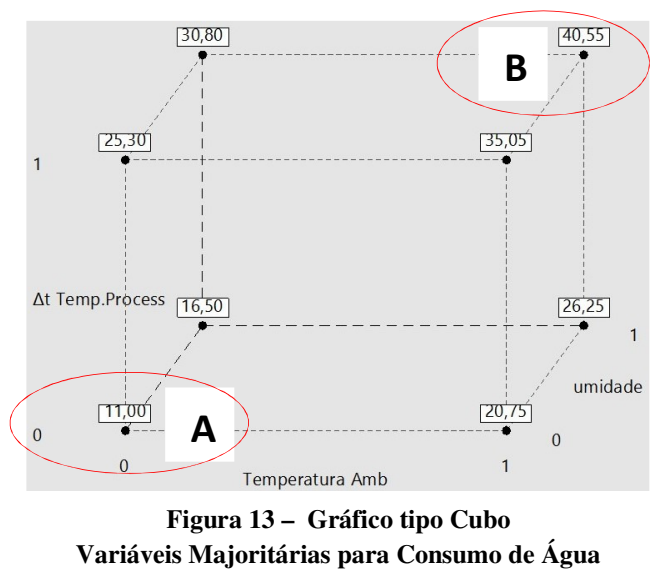

Do mesmo modo, o ponto "B" do gráfico indica o maior consumo de água potável, onde temos as condições atmosféricas desfavoráveis e rejeição térmica elevada (todas variáveis com nível lógico alto $=1$ ).

Por meio do DOE proposto, foi possível também levantar uma equação de regressão do sistema, onde é possível calcular o consumo (makeup) da planta em litros por minutos, dadas as condições atmosféricas e rejeição térmica do sistema. A equação de regressão, apresentada a seguir, possui coeficiente de explicação $\left(R^{2}=94,42 \%\right)$.

Consumo $(1 / \mathrm{min})=[11,00+(9,75 *$ Temp. Amb $)+(14,30 * \Delta \mathrm{t} \mathrm{Temp})+(5,50 *($ umidade $/ 100)] / 100$

\section{Conclusão}

Portanto, por meio da pesquisa e estudo de caso realizado no sistema de água sob pressão do LATC da Cummins Brasil, ficaram caracterizadas as variáveis majoritárias para o consumo de água potável do sistema. Com isso, tendo conhecimento da interação entre as variáveis apresentadas no DOE proposto e levantando os requisitos mínimos e máximos de pressão, temperatura e vazão de água exigidos pelo sistema, foi possível automatizar o processo em questão, por meio do controle do duty cycle, com sensores instalados ao longo da planta e acionamento otimizado das cargas via controladores do tipo PID. 
Embora o consumo de água seja intrínseco a um sistema de refrigeração composto por torres de resfriamento, uma vez que as perdas por evaporação, arraste e purga são inerentes ao processo, é possível atenuar as perdas com o uso consciente dos recursos naturais. Por meio da automação e controle de processos, é possível prover os recursos sem excessos, com pontos de trabalho e operação distintos, em função das condições atmosféricas e da demanda térmica da planta.

O projeto em questão, ainda em andamento, visa prover uma maior economia de água potável, via implementação de uma cisterna interligada à tubulação de purga (blowdown) da estação de tratamento de água. Assim, a água de purga, com alta condutividade e imprópria para o sistema de resfriamento em questão, poderá ser utilizada no abastecimento dos banheiros do prédio (mictórios e descargas).

\section{REFERÊNCIAS}

BENNET, C.O.; MYERS, J. E. Fenômenos de Transporte. São Paulo: McGraw-Hill, 1978.

FOX, Robert W.; MCDONALS, Alan T.; PRITCHARD, Philip J. Mecânica dos Fluídos.6a edição. Rio de Janeiro: LTC, 2006.

OGATA,K. Engenharia de Controle Moderno. 5a edição.São Paulo: Prentice Hall, 2010.

FOUST, A. S.et al Princípio das Operações Unitárias. 2a edição. Rio de Janeiro: LTC, 1982. 